\title{
Efeito do dióxido do carbono, temperatura e armazenamento sobre sementes de soja e micoflora associada ${ }^{1}$
}

\author{
Effect of carbon dioxide, temperature and storage on soybean seeds and associated \\ mycoflora
}

\author{
Raimundo Wagner de Souza Aguiar ${ }^{2 *}$, Deyvid Rocha Brito ${ }^{3}$, Marcio Akio Ootani ${ }^{4}$, Rodrigo Ribeiro Fidelis ${ }^{2}$ e \\ Joenes Nucci Peluzio ${ }^{2}$
}

\begin{abstract}
RESUMO - O desenvolvimento vegetativo e reprodutivo da planta da soja está relacionado à tecnologia de produção de sementes de boa qualidade, com vigor e livres de patogenos. Desse modo, objetivou-se neste trabalho avaliar a efeito do dióxido de carbono $\left(\mathrm{CO}_{2}\right)$ associado à temperatura sobre a micoflora e a qualidade das sementes em diferentes períodos de armazenamento. $\mathrm{O}$ delineamento usado foi inteiramente casualizado em fatorial $(2 \times 3 \times 4)$, sendo duas temperaturas ( 25 e $\left.31^{\circ} \mathrm{C}\right)$, três concentrações de $\mathrm{CO}_{2}\left(0,0 ; 2,5\right.$ e $5,0 \mathrm{~g}$ de $\mathrm{CO}_{2} \mathrm{~kg}^{-1}$ de sementes) e quatro períodos de armazenamento (30; 60; 90 e 120 dias). De acordo com resultados obtidos, observou-se que o dióxido de carbono foi extremamente tóxico para os fungos Aspergillus sp., Fuzarium sp., Coletrochium sp e Penicilium sp., com $100 \%$ de inibição na concentração

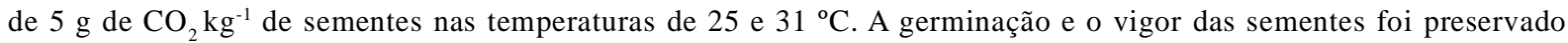
pelo dióxido de carbono, com germinação de $92 \%$ após o período de 120 dias de armazenamento. Enquanto, sementes armazenadas sem $\mathrm{CO}_{2}$ na temperatura de $31{ }^{\circ} \mathrm{C}$, a germinação foi de 44,66\%. A manutenção do vigor e da germinação foi dependente da concentração do $\mathrm{CO}_{2}$ e da temperatura. $\mathrm{O} \mathrm{CO}_{2}$ poderá ser uma tecnologia viável a ser usada para manutenção da qualidade das sementes de soja pelas unidades de beneficiamento de sementes no estado do Tocantins.
\end{abstract}

Palavras-chave: Soja. Plantas-efeito da temperatura. Plantas-armazenamento. Germinação.

\begin{abstract}
The vegetative and reproductive development of the soybean is related to the production technology of good quality seeds which are vigorous and free of pathogens. Thus, this study aimed to evaluate the effect of carbon dioxide $\left(\mathrm{CO}_{2}\right)$ associated with temperature on mycoflora and seed quality for different periods of storage. The design used was a completely randomized factorial $(2 \times 3 \times 4)$, at two temperatures $\left(25\right.$ and $\left.31{ }^{\circ} \mathrm{C}\right)$, three $\mathrm{CO}_{2}$ concentrations $\left(0.0,2.5\right.$ and $5.0 \mathrm{~g} \mathrm{CO}_{2} \mathrm{~kg}^{-1}$ of seed), and four storage periods (30, 60, 90 and 120 days). According with results, it was observed that carbon dioxide was extremely toxic to the fungi Aspergillus sp., Fuzarium sp., Coletrochium sp. and Penicillium sp., with $100 \%$ inhibition at a concentration of $5 \mathrm{~g} \mathrm{CO}_{2} \mathrm{~kg}^{-1}$ of seed, and at temperatures of 25 and $31{ }^{\circ} \mathrm{C}$. Seed germination and vigor were preserved by the carbon dioxide, with $92 \%$ germination after 120 days of storage, while for seeds stored without $\mathrm{CO}_{2}$ at a temperature of $31{ }^{\circ} \mathrm{C}$, germination was $44.66 \%$. The preservation of vigor and germination was dependent on the concentrations of $\mathrm{CO}^{2}$ and on temperature. $\mathrm{CO}_{2}$ may be a viable technology for the preservation of the quality of soybean seeds for seed-processing units in the state of Tocantins.
\end{abstract}

Key words: Soybean. Plants - effect of temperature. Storage - plants. Germination.

\footnotetext{
*Autor correspondência

${ }^{1}$ Recebido para publicação em 27/01/2011; aprovado em 13/02/2012

Pesquisa realizada com o apoio da Universidade Federal do Tocantins-Campus Universitário de Gurupi e a Empresa Talismã

${ }^{2}$ Departamento de Ciências Agrária e Tecnológicas, Universidade Federal do Tocantins, Campus Universitário de Gurupi, Gurupi-TO, Brazil, rwsa@uft.edu.br, fidelisrr@uft.edu.br, joenesp@uft.edu.br

${ }^{3}$ Universidade Federal do Tocantins, Campus Universitário de Gurupi, Gurupi-TO, Brasil, dvbrito06@ hotmail.com

${ }^{4}$ Universidade Federal do Tocantins, Campus Universitário de Gurupi, Gurupi-TO, Brasil, ootani667@uft.edu.br
} 


\section{INTRODUÇÃO}

No Brasil, expansão da cultura da soja (Glycine Max (L) Merril) começou na década de 70. Tornou-se de grande importância na produção de alimentos, como fonte de matéria prima para indústria e alimentação animal (PELÚZIO et al., 2008; ROESSING et al., 1993). O desenvolvimento da cultura da soja está associado a novas tecnologias, principalmente aquelas relacionadas à produção de sementes de qualidade, livres de fitopatógenos, que possam desenvolver plântulas com alto vigor (PELÚZIO et al., 2008).

Fungos podem infestar durante o processamento das sementes e causar várias doenças pós-plantio, dentre os quais mais de 40 espécies de fungos estão associados às sementes. No entanto, somente 15 espécies podem resultar em sérios prejuízos econômicos acelerando o processo de deterioração das sementes e sendo fonte de inóculo primário de infestação de novos plantios (HENNING, 2004).

Diversos fatores influenciam diretamente na viabilidade das sementes durante $\mathrm{o}$ armazenamento, tais como: umidade, temperatura, trocas gasosas, características do tegumento da semente, maturidade, infestação por fungos e insetos, (CALDWELL et al., 2005; DESCHAMPS, 2006; GONÇALVES et al., 2003). Uma das alternativas de conservação da qualidade das sementes é o uso de atmosfera modificada com adição de dióxido de carbono que, dependendo das concentrações, interfere no metabolismo e conserva a germinação das sementes, além de possuir efeito tóxico para a maioria dos organismos presentes nas sementes (AGUIAR et al., 2010; CIRIO; LIMA, 2003; THOMAS et al., 2003, ZARDETTO, 2005).

A produção de sementes de soja no estado do Tocantins está restrita a área de várzeas, sob regime de irrigação subsuperficial, o que favorece a obtenção de sementes de boa qualidade (PELÚZIO et al., 2008). No entanto, devido a existência de uma demanda crescente por sementes livres de patógenos e de alta qualidade, unidade de beneficiamento de sementes (UBS) vem adotando novas tecnologias, a fim de manter a germinação, vigor e sanidade das sementes. Deste modo, este trabalho tem por objetivo avaliar o efeito do dióxido de carbono associado à temperatura sobre a micoflora e a qualidade das sementes de soja em diferentes períodos de armazenamento.

\section{MATERIAL E MÉTODOS}

O presente trabalho foi realizado na Universidade Federal do Tocantins (UFT), Campus Universitário de Gurupi, no período de setembro de 2009 a fevereiro de 2010. As sementes da variedade MONSOY 9144 RR foram obtidas junto à empresa de sementes Talismã Município de Formoso do Araguaia - TO.
$\mathrm{O}$ delineamento experimental utilizado foi $\mathrm{o}$ inteiramente casualizado em fatorial $(2 \times 3 \times 4)$, sendo duas temperaturas $\left(25\right.$ e $\left.31{ }^{\circ} \mathrm{C}\right)$, três concentrações de $\mathrm{CO}_{2}\left(0,0 ; 2,5\right.$ e $5,0 \mathrm{~g}$ de $\mathrm{CO}_{2} \mathrm{~kg}^{-1}$ de sementes $)$ e quatro períodos de armazenamento (30; 60; 90 e 120 dias). As parcelas experimentais foram as combinações entre a temperatura, concentrações de dióxido de carbono e período de armazenamento. Inicialmente foi determinado o grau de umidade $11 \%$, análise de pureza $100 \%$, vigor $98 \%$ e porcentagem de germinação $98 \%$ das sementes a serem usadas nos experimentos. Conforme a Regras para Análise de Sementes (RAS) (BRASIL, 2009).

Para a realização dos experimentos, as sementes foram acondicionadas em câmaras hermeticamente vedadas ao $\mathrm{CO}_{2}$ e $\mathrm{O}_{2}$ com volume de 2 litros, onde o grau de umidade permaneceu durante todo o experimento. $\mathrm{O}$ dióxido de carbono foi injetado de forma direta por meio de um cilindro pressurizado de $\mathrm{CO}_{2}$ até atingir a concentração desejada para cada tratamento $\left(2,5\right.$ e $5,0 \mathrm{~g} \mathrm{de}^{-} \mathrm{CO}_{2} \mathrm{~kg}^{-1} \mathrm{de}$ sementes), sendo controlado por uma balança de precisão de 0,001 g (Modelo MARK 210A, Bel Engineering, Monza-MI, Itália). Nesse experimento, foi levada em consideração a densidade do dióxido de carbono (volume/peso). Logo após a obtenção das concentrações desejadas, as câmaras com as sementes foram vedadas e acondicionadas em câmaras climatizadas de acordo com as temperaturas estabelecidas para cada tratamento.

As avaliações da germinação das sementes foram realizadas em em câmara de germinação em temperatura $27 \pm 1{ }^{\circ} \mathrm{C}$, a partir das sementes acondicionadas nas câmaras, sendo utilizadas 400 sementes, divididas em quatro repetições de 100 sementes. Após 8 dias da semeadura das sementes foram realizadas as avaliações das plântulas normais (BRASIL, 2009).

$\mathrm{O}$ vigor das sementes foi avaliado por meio do teste de tetrazólio com 200 sementes divididas em quatro repetições de 50 sementes. Estas sementes foram préacondicionadas em rolos de papel germitest umedecido, por 16 horas, à temperatura de $25 \pm 0,5^{\circ} \mathrm{C}$ em $\mathrm{BOD}$ (Biochemical Oxygen Demand). Logo após, as sementes foram colocadas em contato com a solução contendo o sal de tetrazólio $(2 ; 3 ; 5$ trifenil cloreto de tetrazólio) na concentração de $0,075 \%$, em seguida foram colocadas em estufa a $41^{\circ} \mathrm{C}$ onde permaneceram por 6 horas de acordo com os procedimentos realizado por Piña-Rodrigues et al. (2004). Após esse período as sementes foram retiradas da estufa e então seccionadas longitudinalmente para se realizar a avaliação. A coloração dos tecidos foi classificada em notas de um a oito, onde o intervalo de um a cinco (sementes viáveis) com alto potencial de germinação. O intervalo de seis a oito (sementes inviáveis) contém somente sementes mortas ou com danos severos no eixo embrionário, não permitindo a germinação normal da semente (FRANÇA; KRZYZABOWSKI; COSTA, 1998). 
Nas sementes armazenadas com dióxido de carbono, inicialmente foram desinfectadas em hipoclorito de sódio $1 \%$ por 30 minutos e álcool etílico a $70 \%$ pelo mesmo período; para cada experimento foram utilizadas 400 sementes divididas em quatro repetições e colocadas em placas de Petri ( $\Phi 120 \mathrm{~mm}$ ) sobre papel filtro e umedecidas em $20 \mathrm{~mL}$ de água destilada. As placas foram deixadas em câmara de incubação com temperatura de $20 \pm 2{ }^{\circ} \mathrm{C}$ e luz branca fluorescente alternada (12 horas de luz/12 horas escuro) durante sete dias segundo Lucca Filho (1987). Em seguida, avaliou-se a incidência de fungos nas sementes com auxílio de microscópio estereoscópico e microscópio composto, e os resultados foram expressos em números de sementes contaminados com cada tipo de fungo.

Os dados referentes à germinação em cada temperatura e nas diferentes concentrações em função do tempo de armazenamento foram submetidos à análise de regressão. Assim, foram geradas as curvas e equações. Já os dados de incidência dos fungos foram transformados em arco seno $\sqrt{x}+1$ e submetidos à análise de regressão. As análises estatísticas foram realizadas por meio do programa estatístico Sisvar 4.6 (FERREIRA, 2001).

\section{RESULTADOS E DISCUSSÃO}

Inicialmente, foram determinada a umidade, a pureza e o potencial de germinação das sementes a serem usadas nos experimentos, conforme informações da metodologia. Onde se encontram esses resultados relacionados aos efeitos do dióxido de carbono sobre a manutenção da germinação das sementes de soja associado às temperaturas $\left(25\right.$ e $\left.31^{\circ} \mathrm{C}\right)$ em diferentes períodos de armazenamento (30; 60; 90 e 120 dias) foi altamente significativo $(\mathrm{P} \leq 0,05)$ (Figura $1 \mathrm{Ae} \mathrm{B})$; com diferenças significativas entre os betas $(\mathrm{P} \leq 0,05)$ das equações de regressão referentes à germinação das sementes de soja nas diferentes temperaturas e às concentrações de dióxido de carbono (Tabela 1).

As sementes de soja mantiveram alto poder germinativo quando armazenadas sob temperatura de $25^{\circ} \mathrm{C}$, principalmente quando associado ao dióxido de carbono, mesmo aplicando a menor dose, evidenciando o efeito do $\mathrm{CO}_{2}$ sobre a manutenção da germinação. Este efeito tornouse mais evidente quando as sementes foram armazenadas sob temperatura de $31^{\circ} \mathrm{C}$ (Figura $1 \mathrm{~B}$ ), sem a presença de $\mathrm{CO}_{2}$ Onde observou-se a redução drástica da porcentagem de germinação, chegando essa a 44,66\% após 120 dias de armazenamento (Figura 1B); independentemente da temperatura de armazenamento, o dióxido de carbono possui efeito positivo na germinação das sementes de soja, o que pode estar associada a interferência direta do $\mathrm{CO}_{2}$ sobre a fisiologia das sementes de soja.

Mussi (2005) avaliou o efeito do $\mathrm{CO}_{2}$ em sementes de girassol e constatou que o dióxido de carbono promoveu redução drástica da taxa de respiração das sementes. Verificou ainda que, o teor de $\mathrm{O}_{2}$ é o principal agente da aceleração da respiração das sementes, e que quanto maior a concentração de dióxido de carbono, existe tendência de se manter a germinação das sementes, pela redução do

Figura 1 - Efeito do dióxido de carbono $\left(\mathrm{CO}_{2}\right)$ sobre a germinação das sementes de soja em diferentes concentrações de $\mathrm{CO}_{2}$ $\left(0,0,2,5\right.$ e 5,0 g de $\mathrm{CO}_{2} \mathrm{~kg}^{-1}$ de sementes), em função do período de armazenamento. Sendo: $\mathbf{A}$ - Germinação das sementes armazenadas a $25^{\circ} \mathrm{C} ; \mathbf{B}$ - Germinação das sementes armazenadas a $31^{\circ} \mathrm{C}$

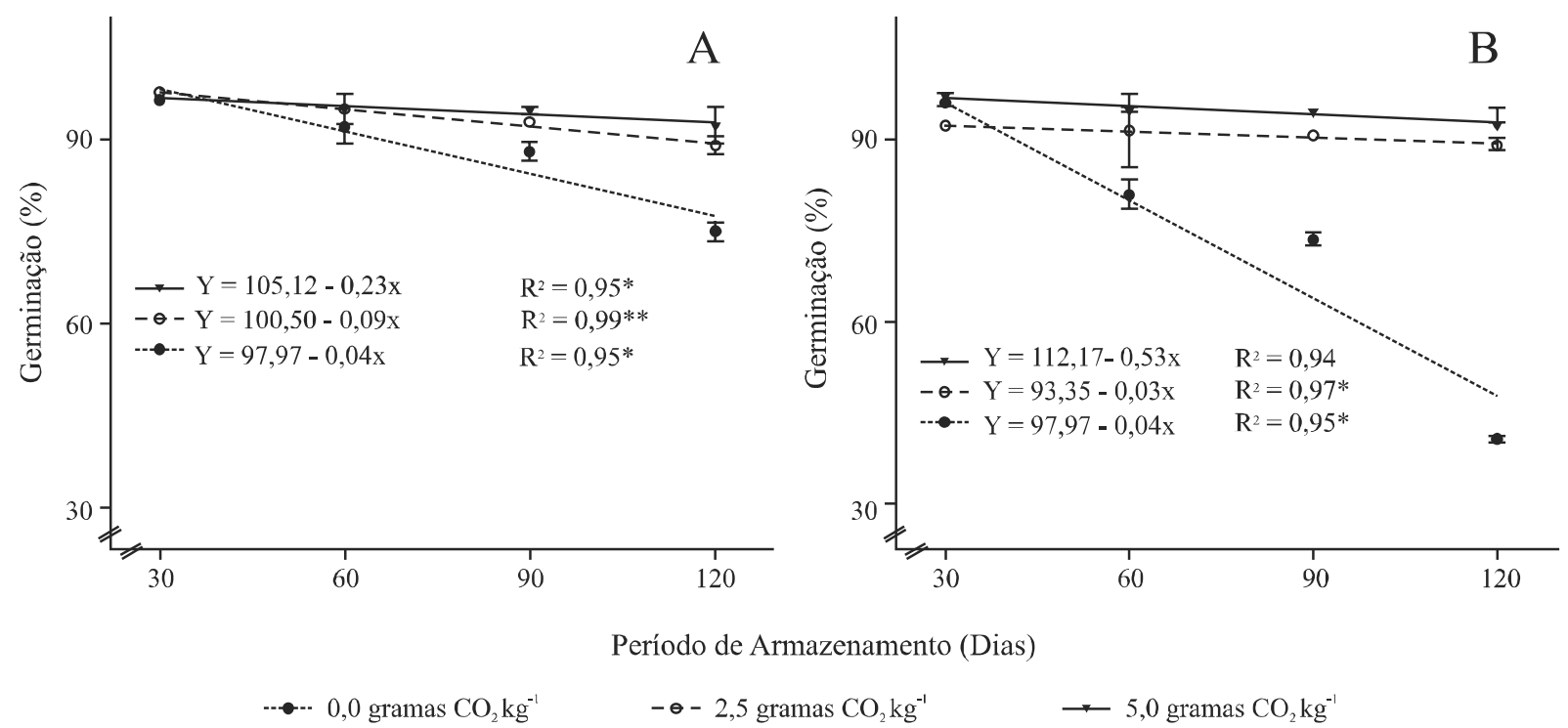


Tabela 1 - Sumário das análises de regressão lineares da germinação $(\mathrm{Y}=a+b \mathrm{x})$ e o efeito do dióxido de carbono em função da temperatura e do período de armazenamento

\begin{tabular}{ccrccccc}
\hline \multirow{2}{*}{ Temp. } & Conc. & \multicolumn{2}{c}{ Parâmetros estimados } & \multirow{2}{*}{ GL } & F & P & $\mathrm{R}^{2}$ \\
\cline { 2 - 4 } $25^{\circ} \mathrm{C}$ & 0,0 & $105,12 \mathrm{a}$ & $-0,23 \mathrm{a}$ & 3 & $20,57^{*}$ & 0,045 & 0,95 \\
& 2,5 & $100,50 \mathrm{a}$ & $-0,09 \mathrm{a}$ & 3 & $131,43^{* *}$ & 0,007 & 0,99 \\
& 5,0 & $97,97 \mathrm{a}$ & $-0,04 \mathrm{a}$ & 3 & $18,90^{*}$ & 0,049 & 0,95 \\
$31^{\circ} \mathrm{C}$ & 0,0 & $112,17 \mathrm{~b}$ & $-0,53 \mathrm{~b}$ & 3 & 15,87 & 0,057 & 0,94 \\
& 2,5 & $93,35 \mathrm{a}$ & $-0,03 \mathrm{a}$ & 3 & $34,53^{*}$ & 0,027 & 0,97 \\
& 5,0 & $97,97 \mathrm{a}$ & $-0,04 \mathrm{a}$ & 3 & $18,90^{*}$ & 0,049 & 0,95 \\
\hline
\end{tabular}

Conc. $=$ Concentração $\left(\mathrm{g}\right.$ de $\mathrm{CO}^{2} \cdot \mathrm{kg}^{-1}$ de semente $), a$ e $b=$ Parâmetros da regressão, $\mathrm{GL}=$ Grau de liberdade, $\mathrm{F}=$ Teste $\mathrm{F}$ da regressão, $(* *, *)$ nível de significância 1 e $5 \%, \mathrm{P}$ = probabilidade da regressão e $\mathrm{R}^{2}=$ Coeficiente determinação de regressão

metabolismo durante o armazenamento, mantendo sua capacidade de germinação ao longo do tempo.

A elevação da temperatura promove aumento da taxa de respiração, afetando consequentemente o poder de germinação das sementes. Segundo Perez-Garcia (2006) a temperatura interfere na aceleração das reações bioquímicas e metabolismos das sementes, pelas quais reservas armazenadas no tecido de sustentação são desdobradas, transportadas e ressintetizadas no eixo embrionário. No entanto, os resultados observados no presente trabalho demonstram que houve diferenças significativas para a temperatura em função da concentração de $\mathrm{CO}_{2}$ quando comparadas com o tratamento sem adição de dióxido de carbono (Figura $1 \mathrm{Ae} \mathrm{B}$ ).

Segundo Rodríguez et al. (2010), os níveis de oxigênio e a elevação do $\mathrm{CO}_{2}$ reduz a atividade metabólica favorecendo a conservação das sementes por períodos de 47; 105 e 160 dias. Os resultados deste trabalho corroboram com aqueles obtidos por Schmidt (2007), que demonstrou que as sementes de espécies florestais tropicais mantidas com baixa concentração de oxigênio, ou conservadas em $\mathrm{CO}_{2}$, diminuem a sua deterioração e envelhecimento das mesmas. Além disso, Rodríguez et al. (2010) demonstraram que a concentração de oxigênio e o aumento da concentração de $\mathrm{CO}_{2}$ reduziram acentuadamente a atividade metabólica das sementes de soja favorecendo a manutenção da qualidade durante o armazenamento.

Analisando os resultados da avaliação do vigor em todos os tratamentos, observa-se que a concentração de $\mathrm{CO}_{2}$ mantém o vigor das sementes durante os períodos de armazenamento. De acordo com os resultados obtidos, não houve diferenças significativas $(\mathrm{P} \leq 0,05)$ para as concentrações de dióxido de carbono $\left(\mathrm{CO}_{2}\right)$, contudo, houve decréscimo no vigor das sementes armazenadas sem dióxido de carbono para as temperaturas de 25 e $31{ }^{\circ} \mathrm{C}$ aos 120 dias após armazenamento (Figura 2 A e B). Os parâmetros das equações de regressão $(b)$ e $(a)$ o vigor e a germinação foram comparados as medias pelo teste de Tukey e não deferiram $(\mathrm{P} \leq 0,05)$ (Tabela 1 e 2).

Segundo Hilhorst et al. (2001) o vigor é uma propriedade fisiológica determinada pelo genótipo e modificada pelo ambiente, que governa sua capacidade de dar rapidamente origem a uma plântula no solo, bem como melhorar sua capacidade de resistir a uma série de fatores ambientais. A influência do vigor da semente pode persistir durante a vida da planta e pode ser afetada durante o período e condições subótimas de armazenamento das sementes. Os resultados com dióxido de carbono sobre o vigor das sementes de soja visualizam um potencial da emergência das plantas com alto vigor, observado durante o desenvolvimento deste trabalho (Figura 2 A e B).

Durante o experimento observou-se se nos períodos de armazenamento houve um decréscimo no vigor e, na germinação das sementes na temperatura de $31^{\circ} \mathrm{C}(\mathrm{P} \leq 0,05)$ comprovando a necessidade da limitação dos fatores que promovam a aceleração da respiração e que afeta diretamente o vigor das sementes; o aumento da taxa respiratória promove redução de energia para emergência das plântulas, diminuindo suas reservas (KOLCHINSKI; SCHUCH; PESKE, 2006). Normalmente, embriões bem formados e com maiores quantidades de energia, formam plântulas mais vigorosas e resistentes às condições adversas do ambiente em que são inseridas (BAUDET, 2003; MUSSI, 2005).

A avaliação do efeito de dióxido de carbono sobre a micoflora presente nas sementes de soja foi realizada em duas temperaturas de armazenagem $\left(25\right.$ e $\left.31{ }^{\circ} \mathrm{C}\right)$, e três concentrações de dióxido de carbono $(0,0 ; 2,5$ e 5,0 $\mathrm{g}_{\text {de }} \mathrm{CO}_{2} \mathrm{~kg}^{-1}$ de sementes), havendo diferenças significativas $(\mathrm{P}<0,05)$ na redução do número de sementes com a presença de fungos durante os períodos de armazenamento (Tabela 3 e 4). 
Figura 2 - Efeito do dióxido de carbono $\left(\mathrm{CO}_{2}\right)$ sobre vigor das sementes de soja submetidas a diferentes concentrações de $\mathrm{CO}_{2}$ $\left(0,0 ; 2,5\right.$ e 5,0 g de $\mathrm{CO}_{2} \mathrm{~kg}^{-1}$ de sementes), em função do período de armazenamento. Sendo: $\mathbf{A}$ - sementes armazenadas a $25^{\circ} \mathrm{C} ; \mathbf{B}^{2}$ - sementes armazenadas a $31{ }^{\circ} \mathrm{C}$

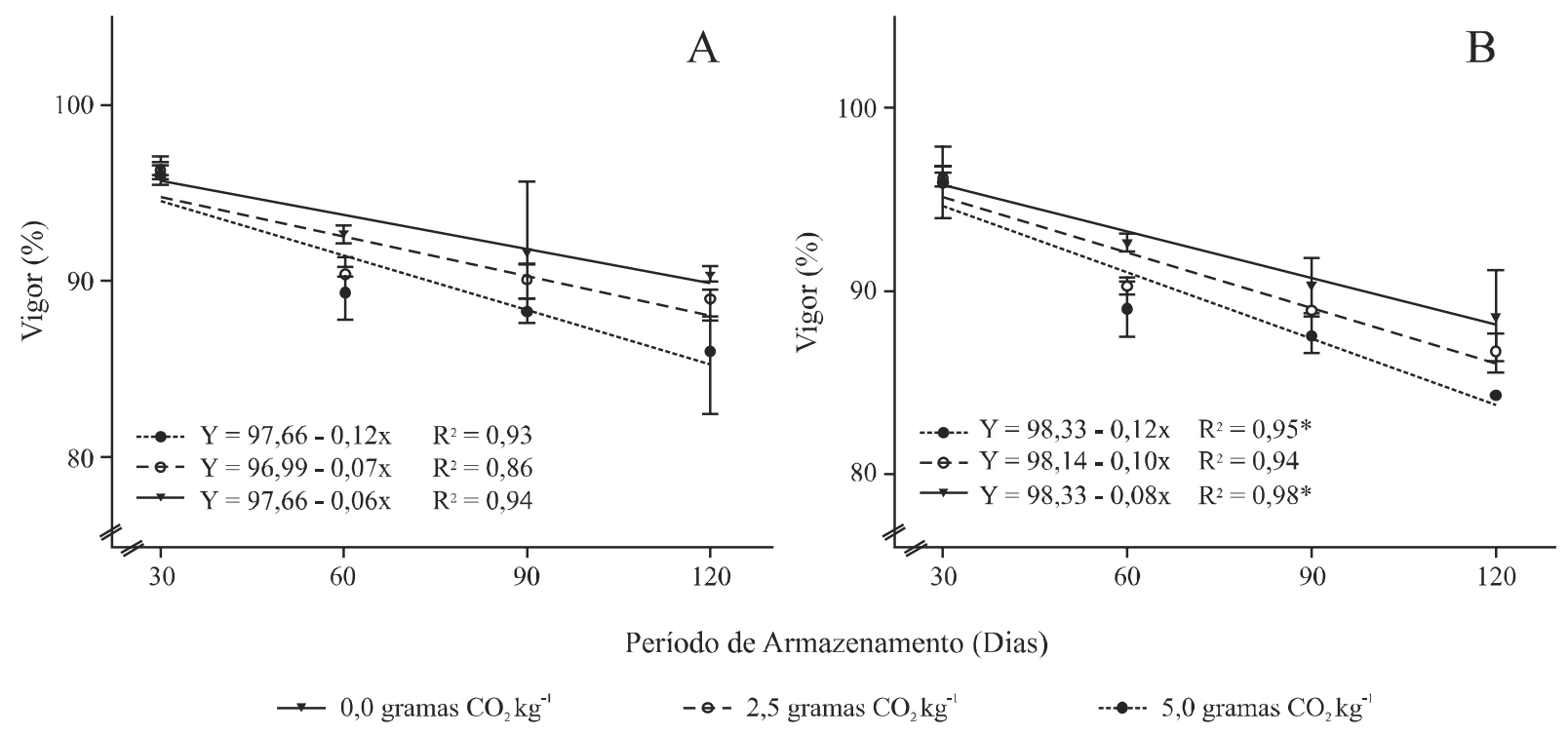

Tabela 2 - Sumário das análises de regressão lineares da germinação $(y=a+b x)$ e o efeito do dióxido de carbono em função da temperatura e do período de armazenamento.

\begin{tabular}{cccccccc}
\hline \multirow{2}{*}{ Temp } & Conc. & \multicolumn{2}{c}{ Parâmetros estimados } & \multirow{2}{*}{ GL } & F & P & \multirow{2}{*}{$\mathrm{R}^{2}$} \\
\cline { 2 - 4 } $25{ }^{\circ} \mathrm{C}$ & 0,0 & $97,66 \mathrm{a}$ & $-0,10 \mathrm{a}$ & 3 & 13,42 & 0,067 & 0,93 \\
& 2,5 & $96,99 \mathrm{a}$ & $-0,07 \mathrm{a}$ & 3 & 6,03 & 0,133 & 0,86 \\
& 5,0 & $97,66 \mathrm{a}$ & $-0,06 \mathrm{a}$ & 3 & 18,32 & 0,050 & 0,94 \\
& 0,0 & $98,33 \mathrm{a}$ & $-0,12 \mathrm{a}$ & 3 & $20,99^{*}$ & 0,044 & $0,95^{*}$ \\
$31^{\circ} \mathrm{C}$ & 2,5 & $98,14 \mathrm{a}$ & $-0,10 \mathrm{a}$ & 3 & 18,07 & 0,051 & 0,94 \\
& 5,0 & $98,33 \mathrm{a}$ & $-0,08 \mathrm{a}$ & 3 & $62,76^{*}$ & 0,015 & $0,98^{*}$ \\
\hline
\end{tabular}

Temp. $=$ Temperatura $\left({ }^{\circ} \mathrm{C}\right)$ e Conc. $=$ Concentração $\left(\mathrm{g} \mathrm{de} \mathrm{CO}^{2} \cdot \mathrm{kg}^{-1}\right.$ de semente), $a$ e $b=$ Parâmetros da regressão, GL $=$ Grau de liberdade, $\mathrm{F}=$ Teste $\mathrm{F}$ da regressão, $\mathrm{P}=$ probabilidade da regressão, $\mathrm{r}^{2}=$ Coeficiente determinação de regressão e $(* * *)$ nível de significância 1 e $5 \%$

$\mathrm{O}$ efeito tóxico do dióxido de carbono foi significativo $(\mathrm{P} \leq 0,05)$ na proliferação dos fungos presente nas sementes de soja, reduzindo de 50 a $100 \%$ a incidência de fungos nas sementes analisadas de acordo com o período de armazenagem (Tabela 3 e 4). O efeito do dióxido de carbono foi mais severo para os fungos Aspergillus sp., Penicillium sp., Fusarium sp e Colletotrichum sp., sendo mais eficiente na concentração de $5,0 \mathrm{~g} \mathrm{~kg}^{-1}$ de sementes, diferenciando em função do período de armazenagem.

Com relação às temperaturas observou-se que a $25{ }^{\circ} \mathrm{C}$ houve uma menor porcentagem de sementes com colônias dos fungos. Segundo Menten (1991) os fungos de grãos armazenados se desenvolvem melhor em temperaturas de 28 a $32{ }^{\circ} \mathrm{C}$; temperatura abaixo apresenta controle bastante efetivo sobre a maioria desses fungos. Em estudos desenvolvidos por Alborch et al. (2011) foi possível observar em grãos de milho, que para fungos de pós colheita Aspergillus niger e Aspergillus carbonarius a temperatura de desenvolvimento foi de 15 a $35^{\circ} \mathrm{C}$.

A temperatura possui efeito direto sobre $o$ desenvolvimento micelial dos fungos sendo que nas temperaturas de 15 a $25{ }^{\circ} \mathrm{C}$ o desenvolvimento dos micélios é totalmente afetado. Os resultados obtidos neste trabalho são semelhantes aos obtidos por Moreno et al. (2000), que observaram que em armazenamento hermético, o desenvolvimento dos fungos cessa quando a concentração 
Tabela 3 - Sumário das análises de regressão lineares de incidência dos fungos associados às sementes de soja em função das concentrações do dióxido de carbono acondicionadas à $25^{\circ} \mathrm{C}$ em vários períodos de armazenamento

\begin{tabular}{|c|c|c|c|c|c|c|c|c|c|}
\hline \multirow{3}{*}{ Fungos } & \multicolumn{9}{|c|}{ Concentração $\mathrm{CO}_{2} \mathrm{~g} \mathrm{~kg}^{-1}$ de sementes à $25^{\circ} \mathrm{C}$} \\
\hline & \multicolumn{3}{|c|}{$0,0 \mathrm{~g} \mathrm{~kg}^{-1}$ de sementes } & \multicolumn{3}{|c|}{$2,5 \mathrm{~g} \mathrm{~kg}^{-1}$ de sementes } & \multicolumn{3}{|c|}{$5,0 \mathrm{~g} \mathrm{~kg}^{-1}$ de sementes } \\
\hline & $\mathrm{R}$ & $\mathrm{F}$ & $\mathrm{R}^{2}$ & $\mathrm{R}$ & $\mathrm{F}$ & $\mathrm{R}^{2}$ & $\mathrm{R}$ & $\mathrm{F}$ & $\mathrm{R}^{2}$ \\
\hline Aspergillus sp. & $Y=1,82+0,001 x$ & 8,09 & 0,89 & $Y=1,85-0,004 x^{*}$ & $26,25^{*}$ & 0,96 & $Y=1,56-0,003 x$ & 10,78 & 0,91 \\
\hline Fusarium sp. & $Y=1,74+0,002 x$ & 14,89 & 0,93 & $Y=1,57-0,002 x$ & 15,34 & 0,94 & $Y=1,52-0,005 x$ & 10,00 & 0,91 \\
\hline Penicillium sp. & $Y=1,55+0,002 x$ & 3,42 & 0,79 & $Y=1,21-0,002 x$ & 3,00 & 0,77 & $Y=0,93-4,0 E-019 x$ & ---- & 1,00 \\
\hline Colletrochium sp. & $Y=1,18+0,002 x$ & 7,73 & 0,89 & $Y=0,93-4,0 E-019 x$ & ---- & 1,00 & $Y=0,93-4,0 E-019 x$ & ----- & 1,00 \\
\hline
\end{tabular}

$\mathrm{R}=$ Equação da regressão linear, $\mathrm{F}=$ Teste $\mathrm{F}$ nível de significância * $(\mathrm{P} \leq 0,05)$, ** $(\mathrm{P} \leq 0,01)$ e $\mathrm{R}^{2}=$ Coeficiente de determinação da regressão

Tabela 4 - Sumário das análises de regressão lineares de incidência dos fungos associados às sementes de soja em função das concentrações do dióxido de carbono acondicionadas à $31^{\circ} \mathrm{C}$ em vários períodos de armazenamento

\begin{tabular}{|c|c|c|c|c|c|c|c|c|c|}
\hline \multirow{3}{*}{ Fungos } & \multicolumn{9}{|c|}{ Concentração $\mathrm{CO}_{2} \mathrm{~g} \mathrm{~kg}^{-1}$ de sementes a $31^{\circ} \mathrm{C}$} \\
\hline & \multicolumn{3}{|c|}{$0,0 \mathrm{~g} \mathrm{~kg}^{-1}$ de sementes } & \multicolumn{3}{|c|}{$2,5 \mathrm{~g} \mathrm{~kg}^{-1}$ de sementes } & \multicolumn{3}{|c|}{$5,0 \mathrm{~g} \mathrm{~kg}^{-1}$ de sementes } \\
\hline & $\mathrm{R}$ & $\mathrm{F}$ & $\mathrm{R}^{2}$ & $\mathrm{R}$ & $\mathrm{F}$ & $\mathrm{R}^{2}$ & $\mathrm{R}$ & $\mathrm{F}$ & $\mathrm{R}^{2}$ \\
\hline Aspergillus sp. & $\mathrm{Y}=1,92+0,001 \mathrm{x}^{* *}$ & $137,28 * *$ & 0,99 & $Y=1,84-0,003 x$ & 10,24 & 0,91 & $Y=1,78-0,006 x$ & 8,42 & 0,89 \\
\hline Fusarium sp. & $Y=1,75+0,002 x$ & 17,00 & 0,94 & $Y=1,78-0,003 x$ & 3,29 & 0,78 & $\mathrm{Y}=1,71-0,007 \mathrm{x}$ & 7,75 & 0,89 \\
\hline Penicillium sp. & $Y=1,63+0,001 x^{*}$ & $44,58 *$ & 0,97 & $Y=1,80-0,007 x$ & 13,16 & 0,93 & $Y=1,46-0,005 x$ & 3,00 & 0,77 \\
\hline Colletotrichum sp. & $\mathrm{Y}=1,52+0,001 \mathrm{x}$ & 9,07 & 0,90 & $Y=1,52+0,001 x$ & 9,07 & 0,90 & $Y=0,93-4,0 \mathrm{E}-019 x$ & ---- & 1,00 \\
\hline
\end{tabular}

$\mathrm{R}=$ Equação da regressão linear, $\mathrm{F}=$ Teste $\mathrm{F}$ nível de significância $*(\mathrm{P} \leq 0,05), * *(\mathrm{P} \leq 0,01)$ e $\mathrm{R}^{2}=$ Coeficiente de determinação da regressão

de oxigênio é reduzida para $1 \%$. Enquanto, o dióxido de carbono a 80 e $20 \%$ o oxigênio possui forte efeito do sobre a esporulação de Mucor plumbeus, Fusarium oxysporum, Byssochlamys fulva, Byssochlamys nivea, Penicillium commune, Penicillium roqueforti, Aspergillusflavus, Eurotium chevalieri $\mathrm{e}$ Xeromyces bisporus (TANIWAKI et al., 2009).

Cairns-Fuller, Alfred e Magan (2005) relatam que as espécies de Aspergillus e Penicillium, podem causar danos diretos às sementes e na germinação, com o aumento da taxa de ácidos graxos e produção de toxinas, com resultados expressivos na redução da germinação de soja (YORINORI, 1982). Deste modo, verifica-se diferença na suscetibilidade das espécies de fungo encontradas nas sementes de soja ao dióxido de carbono. Tornando-se necessários estudos para estabelecer concentrações de $\mathrm{CO}_{2}$ que venham a eliminar todas as fontes de inóculo presentes nas sementes.

O efeito tóxico do dióxido de carbono sobre o desenvolvimento dos fungos ainda não está completamente elucidado. Estudos demonstram que mesmo em altas concentrações de dióxido de carbono, dependendo da concentração do oxigênio, não limitam completamente o desenvolvimento de algumas espécies de fungos (HOOGERWERF et al., 2002; TANIWAKI et al., 2009, 2010). Neste caso, para os fungos Aspergillus sp., Fusarium sp., Penicillium sp. e Coletrochium musae são necessários estudos da concentração de oxigênio para correta eliminação dos mesmo.

\section{CONCLUSÕES}

1.O dióxido de carbono foi altamente eficiente sobre a manutenção da germinação e vigor das sementes de soja durante armazenagem;

2.O dióxido de carbono e a temperatura de $25^{\circ} \mathrm{C}$ inibiu a maioria dos fungos presentes nas sementes de soja, após um período de 120 dias.

\section{REFERÊNCIAS}

AGUIAR, R. W. S. et al. Toxicidade da combinação de dióxido de carbono e fosfina sob diferentes temperaturas para Tribolium castaneum. Revista Brasileira de Engenharia Agrícola e Ambiental, v. 14, n. 08, p. 32-129, 2010.

ALBORCH, L. et al. Effect of water activity, temperature and incubation time on growth and ochratoxin A production by Aspergillus niger and Aspergillus carbonarius on maize kernels. International Journal of Food Microbiology, v. 147, n. 01, p. 53-57, 2011. 
BAUDET, L. Armazenamento de Sementes. In: PESKE, S. T.; ROSENTHAL, M. D.; ROTA, G. M. (Ed.). Sementes: fundamentos científicos e tecnológicos. Pelotas: Gráfica Universitária-UFPel, 2003. p. 369-418.

BRASIL. Ministério da Agricultura, Pecuária e Abastecimento. Regras para análise de sementes/Ministério da Agricultura, Pecuária e Abastecimento. Secretaria de Defesa Agropecuária. - Brasília: Mapa/ACS, 2009. 399 p.

CAIRNS-FULLER, V.; ALDRED, D.; MAGAN, N. Water, temperature and gas composition interactions affect growth and ochratoxin A production by isolates of Penicillium verrucosum on wheat grain. Journal of Applied Microbiology, v. 99, n. 05, p. 1215-1221, 2005.

CALDWELL, C. R. et al. Effect of Temperature, Elevated Carbon Dioxide, and Drought during Seed Development on the Isoflavone Content of Dwarf Soybean [Glycine max (L.) Merrill] Grown in Controlled Environments. Journal of agricultural and food chemistry. v. 53, n. 04, p. 1125-1129, 2005.

CIRIO, G. M.; LIMA, M. L. R. Z. C. Métodos de detecção do gênero Aspergillus em sementes de milho (Zea mays L.) em 270 dias de armazenamento. Visão Acadêmica, v. 04, n. 01, p. 19-23, 2003.

DESCHAMPS, L. H. Qualidade da semente de soja e de seu repasse beneficiados em mesa de gravidade. $2006.46 \mathrm{f}$. Dissertação (Mestrado em Ciências e Tecnologia de sementes). - Faculdade de Agronomia Eliseu Maciel. Universidade Federal de Pelotas, Pelotas, 2006.

FERREIRA, D. F. Sistema de análises de variância para dados balanceados. Lavras: UFLA, 2001. (SISVAR 4. 1. pacote computacional).

FRANÇA NETO, J. B.; KRZYZANOWSKI, F. C.; COSTA, N. P. O teste de tetrazólio em sementes de soja. Londrina: EMBRAPA-CNPSo, 1998. 71 p. (Documentos, 115).

GONÇALVES, R. A. et al. Controle de Rhyzopertha dominica pela atmosfera controlada com $\mathrm{CO}_{2}$ em trigo. Pesquisa Agropecuária Brasileira, v. 35, n. 01, p. 01-09, 2003.

HENNING, A. A. Patologia e tratamento de sementes: noções gerais. Londrina: Embrapa Soja, 2004. 51 p. (Documentos, 235).

HILHORST, H. W. M. et al. Curso avançado em fisiologia e tecnologia de sementes. Lavras: UFLA, 2001. p. 74.

HOOGERWERF, S. W. et al. High oxygen and high carbon dioxide containing atmospheres inhibit growth of food associated moulds. Letters in Applied Microbiology, v. 35, n. 05, p. 419-422, 2002.

KOLCHINSKI, E. M.; SCHUCH, L. O. B.; PESKE, S. T. Crescimento inicial de soja em função do vigor das sementes. Revista Brasileira Agrociência, v. 12, n. 02, p. 163-166, 2006.

LUCCA FILHO, O. A. Testes de sanidade de sementes de milho. In: SOAVE, J.; WETZEL, M.M.V. da S. Patologia de sementes. Campinas: Fundação Cargill/ ABRATESCOPASEM, 1987. p. 430-440.
MENTEN, J.O.M. Prejuízos causados por patógenos associados às sementes. In: MENTEN, J.O.M. (Ed). Patógenos em sementes: detecção, danos e controle químico. Piracicaba: FEALQ, 1991. p.115-36.

MORENO, M. E.; JIMENEZ, A. S.; VAZQUEZ, M. E. Effect of Sitophilus zeamais and Aspergillus chevalieri on the oxygen level in maize stored hemetically. Journal Stored Product Research, Oxford, v. 36, n. 01, p.25-36, 2000.

MUSSI, M. M. Germinação e vigor de sementes de girassol (Helianthus annuus L.) submetidas a diferentes concentrações de $\mathrm{CO}_{2}$, períodos de exposição e embalagens. 2005. 66f. Dissertação (Mestrado em Agronomia, Produção Vegetal) - Centro de Ciências Agrárias, Universidade Federal do Paraná, Paraná, 2005.

PELÚZIO, J. M. et al. Comportamento de cultivares de soja sob condições de várzea irrigada no sul do estado do Tocantins, Entressafra 2005. Bioscience Journal, v. 24, n. 01, p. 75-80, 2008.

PEREZ-GARCIA, F.; GONZALEZ-BENITO M. E. Seed germination of five Helianthemum species: Effect of temperature and presowing treatments, Journal of Arid Environments, v. 65, n. 01, p. 688-693, 2006.

PIÑA-RODRIGUES, F. C. M. et al. Embebição e reativado do metabolismo. In: FERREIRA, A. G.; BORGHETTI, F. (Org.). Germinação do básico ao aplicado. Porto Alegre: Artmed, 2004. p. 283-297.

RODRÍGUEZ, J. C. et al. Almacenaje de granos en bolsas plásticas: sistema silobag. EEA INTA Balcarce. Disponível em: <http://www.engormix.com>. Acesso em: 30 nov. 2010.

ROESSING, A. C.; GUEDES, L. C. A. Aspectos Econômicos do Complexo Soja: sua participação na Economia Brasileira e evolução na região do Brasil Central. In: ARANTES, N. E; SOUZA, P.I. de M. Cultura da Soja nos Cerrados. Piracicaba: Associação Brasileira para a Pesquisa da Potassa e do Fosfato., 1993.

SCHMIDT, L. Tropical forest seed. Dinamarca: DFSC, 2007. 421 p.

TANIWAKI, M. H. et al. Growth and mycotoxin production by food spoilage fungi under high carbon dioxide and low oxygen atmospheres. International Journal of Food Microbiology, v. 132, n. 02/03, p. 100-108, 2009.

TANIWAKI, M. H. et al. Growth and mycotoxin production by fungi in atmospheres containing $80 \%$ carbon dioxide and $20 \%$ oxygen. International Journal of Food Microbiology, v. 143, n. 03 , p. $218-225,2010$.

THOMAS, J. M. et al. Elevated temperature and carbon dioxide effects on soybean seed composition and transcript abundance. Crop Science. v. 43, n. 04, p. 1548-1557, 2003.

YORINORI, J. T. Doenças da soja causadas por fungos. Informe Agropecuário, v. 08, n. 02, p. 40-46, 1982.

ZARDETTO, S. Effect of modified atmosphere packaging at abuse temperature on the growth of Penicillium aurantiogriseum isolated from fresh filled pasta. Food Microbiology, v. 22, n. 01, p. 367-371, 2005. 